\title{
Free-Cationic Polymerization of Styrere by Radiation
}

\author{
Kanae Hayashi, Koichiro Hayashi, and Seizo OKamura \\ Osaka Laboratory for Radiation Chemistry, Japan Atomic Energy \\ Research Institute, 508, Mii, Neyagawa, Osaka, Japan.
}

(Received August 7, 1972)

\begin{abstract}
The cationic polymerization of bulk styrene by radiation has been investigated by dilatometry and electrical conductivity measurements.

In the sample which attained the highest polymerization rate, $R_{\mathrm{p}}$ in this study the dose rate exponent of $R_{\mathrm{p}}$ was still 0.7, however, a 0.6-power dependence was obtained in oxygen containing samples in which $R_{\mathrm{p}}$ in higher dose rate region was considerably lower than that of oxgen-free one. In well-dried, oxygen-free samples, a non-Ohmic current-voltage relationship was observed. These behaviors can be explained by the coexistence of polymeric anions as well as polymeric cations in well-dried, oxygen-free system. Kinetic calculations of the rate constant for propagation, $k_{\mathrm{p}}$ and its activation energy, $E_{\mathrm{p}}$ were made giving $k_{\mathrm{p}}=(2.4 \pm 0.9) \times 10^{6} / \mathrm{mol}^{-1} \mathrm{sec}^{-1}$, and $E_{\mathrm{p}}=2.2 \pm 1.3 \mathrm{kcal}$ $\mathrm{mol}^{-1}$.

From the comparison with the previously reported $k_{\mathrm{p}}$ values with other polymerization mechanisms, it is found that $k_{\mathrm{p}}$ with free-cationic mechanism is the highest probably because of its low $E_{\mathrm{p}}$ values.
\end{abstract}

KEY WORDS Cationic Polymerszation / Radiation / Free Ion / Styrene / Electrical Conductivity / Effect of Oxygen / Termination Reactions / Propagation Rate Constant / Activation Energy / Propagation Mechanism /

It has been recognized that radiation-induced polymerization of vinyl compounds proceeds by a free-ionic mechanism in contrast with the paired-ionic mechanism which is initiated by catalyst. Many studies in this field gave evidences for it on the basis of the following reasons. 1. The polymerization is retarded by a trace of polar impurity especially water. ${ }^{1-4}$ The extreme purification or drying to remove a trace amounts of polar impurities from monomers is also required for a free-anionic polymerization intitiated by a catalyst. 2 . The half-power dependence of $R_{\mathrm{p}}$ on dose rate can be achieved ultimately. ${ }^{5-8}$ This is strong confidence for the free-ionic polymerization in the system where an ionic mechanism has already been established. 3 . The polymerization takes place with a sufficiently high reaction rate in nonpolar medium, ${ }^{1-8}$ while in such a medium the paired-ionic polymerization proceeds at a very low rate because of slight dissociation of catalyst. 4. The propagation rate constants, $k_{\mathrm{p}}$ evaluated by scavenger $^{4,9}$ and electrical conductivity ${ }^{6.10}$ methods are in the region between $10^{5}$ and $10^{8} \mathrm{lmol}^{-1} \mathrm{sec}^{-1}$. These values are very large in comparison with those in paired-cation, paired-anion and radical polymerization. $^{10} 5$. In the field of radiation chemistry, the existence of free ion has been confirmatively established experimentally ${ }^{11-13}$ as well as theoretically ${ }^{14}$ while ion-pair state has not yet been suggested as a stable intermediate. If there were to coexist paired ions with free ions generated by ionizing radiation, the total ion yield should be less than 3-4 ions par $100-\mathrm{eV}$ energy absorbed. Taking account of the freeion yield, around 0.1 in nonpolar medium, the population of paired ions, if it exists, 30-40 times greater than that of free ion at most. As $k_{\mathrm{p}}$ values in free-ionic polymerization is probaby $10^{2}-10^{3}$ times greater than that in paired-ionic one, the contribution from paired-ionic polymerization can be neglected in the total rate of polymerization.

In the preceding papers ${ }^{6,10}$ the estimation method of $k_{\mathrm{p}}$ by combining the determinations of $R_{\mathrm{p}}$ had been proposed through dilatometry 
and of the free-ion lifetime through the steadystate electrical conductivity under irradiation. It has been found that the activation energy, $E_{\mathrm{p}}$, of free-cationic propagation in isobutyl vinyl ether (IBVE) ${ }^{6}$ was strikingly large in comparison with those in the other vinyl monomers such as styrene. However, as it is known that vinyl ethers sometimes show contrasting polymerization behaviours with respect to those of other monomers, ${ }^{15}$ the polymerization studies on vinyl monomers other than vinyl ethers by radiation have been required to clarify the general features of free-cationic polymerization.

On the other hand, styrene is one of most popular vinyl monomers and is well known to be capable of polymerization via all kinds of mechanisms, free radical, anionic and cationic, wherein the latter two are divided into ion-pair and free-ionic mechanisms, respectively. In the case of styrene, kinetic results such as $k_{p}$ and $E_{\mathrm{p}}$ values have been reported in all of these polymerization mechanisms except the freecationic one. A crude evaluation of $k_{\mathrm{p}}$ in radiation-induced cationic polymerization was carried out previously, ${ }^{10}$ while evaluation of $E_{\mathrm{p}}$ has not yet been made. In this work the free-cationic polymerization of styrene by radiation was carried out in order to elucidate features of the free-cationic polymerization in contrast to those of other mechanisms. In particular the largest concern of the author rests on the chain propagation step in the free-cationic mechanism.

\section{EXPERIMENTAL}

Some improvements were attempted in order to achieve the superdry state as compared with our former procedure ${ }^{6}$ for isobutyl vinyl ether. Modifications of the vacuum system gave a rise of the vacuum level down to $3 \times 10^{-7} \mathrm{mmHg}$ in a few hours after evacuation of the system. The vacuum-line system was always heated at about $200^{\circ} \mathrm{C}$ with a wound heater. Styrene was dried by repeated contact with the drying agent dried by baking before use. A sampling ampoule and a dilatometer cell were baked at $400^{\circ} \mathrm{C}$ and at $200^{\circ} \mathrm{C}$, respectively, in the vacuum system for more than $20 \mathrm{hrs}$ and the remaining part was carefully and thoroughly backed out with a flame. The well-dried monomer was sealed in an ampoule or the dilatometer cell after a vacuum level less than $1 \times 10^{-6} \mathrm{mmHg}$ was confirmed.

Silica gel (SG) or molecular shieves (MS) 3A was used as drying agents as well as barium oxide $(\mathrm{BaO})$ after baking out at $400^{\circ} \mathrm{C}$ for more than two days in high vacuum. These drying agents, except for $\mathrm{BaO}$, initiate the polymerization slowly and their surfaces become covered with polymer when monomer was stored over them for a long period. Accordingly, in order to avoid polymerization, styrene was usually stored over $\mathrm{BaO}$ in vacuo, and then further dried over SG or MS before use. In the purification of monomers the purity of the sample was little affected by the kind of drying agent used but depended significantly on the drying conditions adopted in the procedures required for vacuum distillation or sampling.

The drying and sampling treatments for each sample studied are summarized in Table I. In the case of sample $D$, the dried monomer which received an accidental contamination with air was again treated with silica gel after degassing and vacuum distilled into the cell. In sample

Table I. Preparation procedures of polymerization samples

\begin{tabular}{cll}
\hline Sample & \multicolumn{1}{c}{ Drying } & \multicolumn{1}{c}{ Sampling } \\
\hline $\mathrm{A}$ & $\mathrm{BaO}(11$ months $) \rightarrow \mathrm{SG}(5$ days $) \rightarrow \mathrm{SG}(5$ days $)$ & Degassed \\
$\mathrm{B}$ & $\mathrm{BaO}(11$ months $) \rightarrow \mathrm{SG}(17$ days $) \rightarrow \mathrm{SG}(6$ days $) \rightarrow \mathrm{SG}(5$ days $)$ & Degassed \\
$\mathrm{C}$ & $\mathrm{BaO}(2.5$ months $) \rightarrow \mathrm{MS}(9$ days $) \rightarrow \mathrm{BaO}(5$ days $) \rightarrow \mathrm{BaO}(3$ days $)$ & $\begin{array}{l}\text { Equilibrated with } \\
\text { oxygen }(10 \text { mmHg })\end{array}$ \\
$\mathrm{D}$ & $\mathrm{BaO}(9$ days $) \rightarrow \mathrm{SG}(88 \text { days })^{\mathrm{a}} \rightarrow \mathrm{SG}(13$ days $)$ & Degassed \\
$\mathrm{E}$ & $\mathrm{BaO}^{\mathrm{a}} \rightarrow \mathrm{MS}(3$ months $) \rightarrow \mathrm{MS}(10$ days $)$ & Degassed, insufficiently dried cell \\
$\mathrm{F}$ & $\mathrm{SG}$ in the presence of air & Degassed, insufficiently dried cell ${ }^{\mathrm{b}}$ \\
\hline
\end{tabular}

a Contaminated with air and moisture during storage.

b Cell was evacuated for 2 hrs. without heating. 
$\mathrm{C}$, the monomer was kept in equilibrium with dry oxygen (ca. $10 \mathrm{mmHg}$ ) after transferring into the cell and sealed off. In sample F, insufficiently dried monomer was introduced into the cell which had been evacuated only for two hours without heating the system.

Further details of the experimental procedures concerning dilatometry and electrical conductivity measurements were described in the preceding paper. ${ }^{6}$

Polymers for molecular weight determinations were prepared by ${ }^{60} \mathrm{Co} \gamma$-ray polymerization in vacuum at $0^{\circ}, 25^{\circ}$, and $50^{\circ} \mathrm{C}$, respectively. Vapor pressure osmometry was carried out using a Hewlet Packard Model 502 osmometer in toluene solutions at $30^{\circ} \mathrm{C}$.

\section{RESULTS}

Determinations of the rate of polymerization, $R_{\mathrm{p}}$ and specific conductivity, $\sigma$ as a function of dose rate have been carried out at $25^{\circ} \mathrm{C}$ for six separate samples, A-F, whose characteristics are given in Table I. The $\sigma$ values are given as a function of dose rate in Figure 1. In welldried samples as $\mathbf{A}$ and $\mathrm{B}$, there observed $\mathbf{a}$ decrease of specific conductance at the high voltage region studied, in spite of relatively large scatter in its value. It is striking that such a non-Ohmic current-voltage relationship was observed in the system of ionic conduction. On the other hand, an Ohmic relation was found to be maintained in samples $C, E$, and F which supposedly contain relatively large amount of impurities, probably oxygen and/or water. Sample D was an intermediate case in which Ohmic relation was maintained at a higher dose rate.

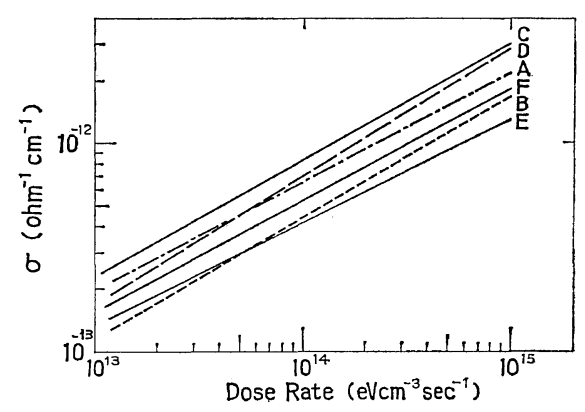

Figure 1. Specific conductance vs. dose rate in styrene at $25^{\circ} \mathrm{C}$; field strength, $100 \mathrm{Vcm}^{-1}$.
The non-Ohmic relation found in the present study was not observed for the polymerization systems studied previously. ${ }^{6,16}$ It is also striking that $\sigma$ values considerably vary with the purification grade of samples. From the curves $C$ and $F$, it is found that mobility of oxygen anion is probably considerably greater than that of impurity cation. However as the $\sigma$ value is a sum of the concentrations of ionic species multiplied by their mobilities, it is not easy to discuss the differences in the quality and quantity of charged species in each sample from the absolute values of $\sigma$. Relatively high dose rate component of $\sigma$ seems also characteristic to these polymerization systems: $0.53,0.59,0.57,0.62$, 0.50 , and 0.55 in samples $\mathrm{A}, \mathrm{B}, \mathrm{C}, \mathrm{D}, \mathrm{E}$, and $\mathrm{F}$, respectively at the field of $100 \mathrm{~V} \mathrm{~cm}^{-1}$. It has been kinetically shown that the dose-rate exponent of $\sigma$ is always 0.5 when there exists a sole charge carrier both for positive and negative species. ${ }^{11,12}$ In other words, a deviation of the dose-rate exponet of $\sigma$ from 0.5 indicates the coexistence of several kinds of ionic species and interactions between them must be taken into account in the polymerization systems studied.

In Figure 2 the rate of polymerization, $R_{\mathrm{p}}$ at $25^{\circ} \mathrm{C}$ as a function of the dose rate $(I)$ is shown for three samples which are prepared in vacuum. Sample F did not polymerize with sufficiently high reaction rate for the ionic polymerization of styrene. In sample E, the dose-rate exponent

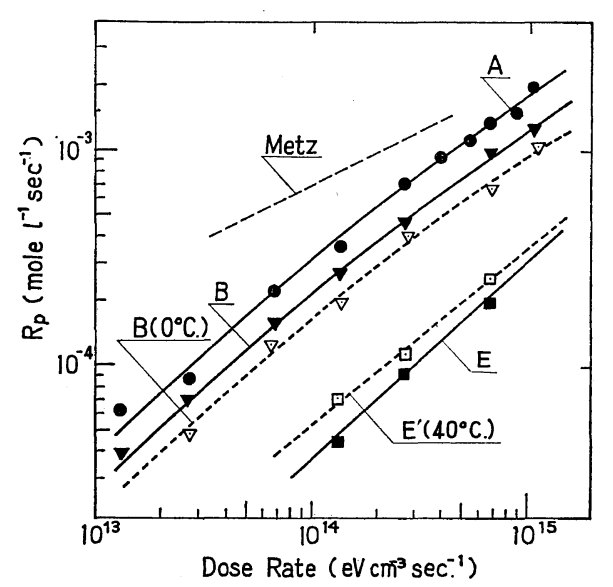

Figure 2. $R_{\mathrm{p}}$ at $25^{\circ} \mathrm{C}$ vs. dose rate in vacuum prepared samples. 
of $R_{\mathrm{p}}$ is approximately 1 , indicating predominance of impurity termination. In sample A and B the $R_{\mathrm{p}}-I$ relationships are given by curved lines; their dose rate exponents become lower at higher dose rate and comparing with sample $\mathrm{E}$ at a fixed dose rate, $\boldsymbol{R}_{p}$ 's are considerably higher while their dose rate exponents are lower. These $R_{\mathrm{p}}-I$ relationships observed well coincide with the kinetic results described previously. ${ }^{6}$ In this study the highest $R_{\mathrm{p}}$ was attained in sample $\mathrm{A}$, in which the rate exponent is still 0.7 at higher dose rate region in spite of rigorous drying and careful sampling procedure. The highest limit of $R_{\mathrm{p}}{ }^{*}$ in styrene indicated by the power dependence of $R_{\mathrm{p}}$ on dose rate, has been achieved by $\mathrm{Metz}^{8}$ and is shown with broken line in Figure 2. The experimental system employed, however, seems to require several attempts and modification of the system to achieve the superdry state. Drying of the dilatometer cell which can not be heated above $250^{\circ} \mathrm{C}$ is considered to be still incomplete. It seems to be essential to heat the whole vacuum system at high temperature under high vacuum for long time in order to achieve the superdry state. And a slight unnoticed difference in drying or sampling procedures possibly gives a decrease in $R_{\mathrm{p}}$ as shown in sample $B$ as compared with that of sample $A$.

When air or oxygen is present in the system, polymerization behaviors change as shown in Figure 3. In the case of sample D which was sealed in vacuum, $R_{\mathrm{p}}-I$ relationship is appar-

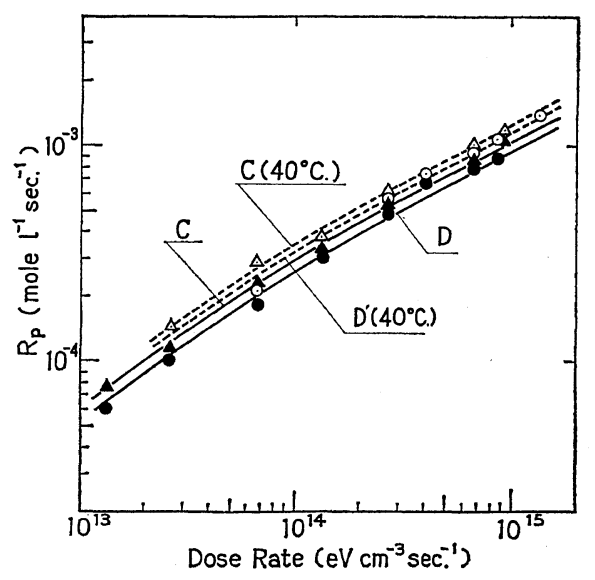

Figure 3. $R_{\mathrm{p}}$ at $25^{\circ} \mathrm{C}$ vs. dose rate in oxygen containing samples. ently similar to that of sample $\mathrm{C}$ indicating insufficient removal of air during the degassing process prior to the final drying with silica gel. Comparing with the $R_{\mathrm{p}}-I$ curves in Figure 2, it is clear that $R_{\mathrm{p}}$ 's in oxygen containg samples are higher at low dose-rate region while at high dose-rate region $R_{\mathrm{p}}$ 's become lower. The doserate exponent of sample $\mathrm{C}$ at higher dose-rate region is 0.6 though $R_{\mathrm{p}}$ is still lower than that of sample A. In other words, $R_{\mathrm{p}}-I$ curves in sample $A$ and $C$ intersect each other and such a behavior cannot be explained with the previously proposed kinetics. ${ }^{6,10}$

The polymerization was carried out at $25^{\circ}$ and $40^{\circ} \mathrm{C}$ in samples $\mathrm{C}, \mathrm{D}$, and $\mathrm{E}$ and at $25^{\circ}$ and $0^{\circ} \mathrm{C}$ in sample $\mathrm{B}$, which are also shown in Figures 2 and 3. It is apparent that $R_{\mathrm{p}}$ increases with temperature. $R_{\mathrm{p}}-I$ curves $\mathrm{B}, \mathrm{C}$, and $\mathrm{D}$ can be regarded to be almost parallel to the curves $B^{\prime}, C^{\prime}$, and $D^{\prime}$, respectively. This indicates that the contribution of impurity termination to total termination rate at a fixed dose rate is almost invariant with temperature. In Figure 4, relative values of $R_{p}\left(40^{\circ} \mathrm{C}\right)$ to $R_{\mathrm{p}}$ $\left(25^{\circ} \mathrm{C}\right)$ and $R_{\mathrm{p}}\left(0^{\circ} \mathrm{C}\right)$ to $R_{\mathrm{p}}\left(25^{\circ} \mathrm{C}\right)$ were plotted as a function of the dose rate. It was found that the relative values of $R_{p}$ are regarded as independent of dose rate at 0 and $40^{\circ} \mathrm{C}$ in spite of considerable scattering in thier values. The relative polymerization rate to $25^{\circ} \mathrm{C}$ are 0.75 at $0^{\circ} \mathrm{C}$ and 1.18 at $40^{\circ} \mathrm{C}$ on the average. The temperature coefficient of $R_{\mathrm{p}}$ in oxygen containing samples (C and D) between $25^{\circ}$ and $40^{\circ} \mathrm{C}$ agreed well with that in oxygen free sample (B) between $0^{\circ}$ and $25^{\circ} \mathrm{C}$. This suggests that the

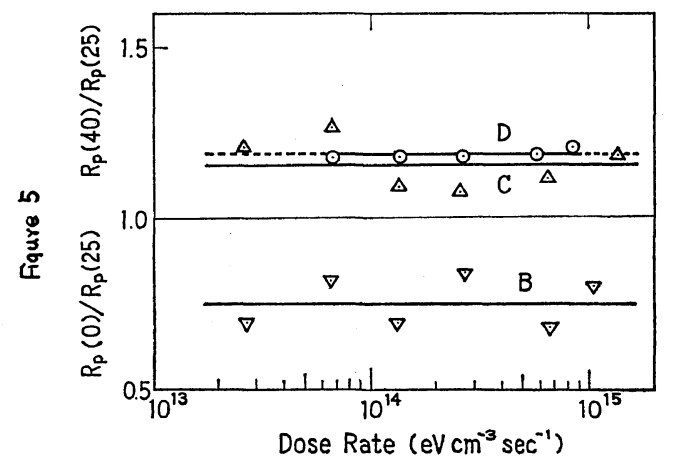

Figure 4. Relationship between the the relative $R_{\mathrm{p}}$ value and dose rate. 
polymerization mechanism is almost similar in both cases though the absolute rate of each elementary reaction are different. The apparent activation energy of polymerization, $E_{\text {app }}$ was evaluated to be $1.6 \pm 0.7 \mathrm{kcal} \mathrm{mol}^{-1}$.

Number-average molecular weights of polymers obtained at $0^{\circ}, 25^{\circ}$, and $40^{\circ} \mathrm{C}$ were determined to be $5.00,5.39$, and $3.91 \times 10^{4}$, respectively. From the polymerization rates, impurity levels of these samples were found to be almost the same, corresponding to a little lower level than that of sample B shown in Figure 2. Recently, Huang ${ }^{17}$ reported that the molecular weight increases with increasing polymerization temperature from $-29^{\circ}$ to $-10^{\circ} \mathrm{C}$ with an apparent activation energy of $0.15 \mathrm{kcal} \mathrm{mol}^{-1}$. From our values at $0^{\circ}$ and $25^{\circ} \mathrm{C}$, we can see that this trend is maintained to a little higher temperature though the absolute values in his determination seems to be a little higher than ours taking account of the temperature difference. If the molecular weight at low temperature polymerization is governed solely by chain-transfer reaction to monomer, a considerable decrease in our molecular weight at $40^{\circ} \mathrm{C}$ may suggeest a slight involvement of another molecular-weight-determining process. However considering the polymerization rates, it is evident that the molecular weights of these polymers were governed predominantly by the chain-transfer reaction to monomer, and the obtained results as to molecular weight and its temperature dependence should give clue to that reaction in styrene.

\section{DISCUSSION}

\section{Reaction Mechanism}

In the former paper ${ }^{6}$ on vinyl ether, the polymerization behavior such as $R_{\mathrm{p}}-I$ relationship had been well explained in terms of two competitive termination reactions.

$$
\begin{aligned}
& \mathrm{M}_{n}^{+}+\mathrm{Y}^{-} \stackrel{k_{\mathrm{r},(\mathrm{n})}}{\longrightarrow} \mathrm{M}_{n}-\mathrm{Y} \text { or } \mathrm{M}_{n}+\mathrm{Y}^{\prime} \\
& \mathrm{M}_{n}^{+}+\mathrm{X} \stackrel{{ }^{k_{\mathrm{X}}}}{\longrightarrow} \mathrm{M}_{n}+\mathrm{X}^{+}
\end{aligned}
$$

where $\mathrm{X}$ and $\mathrm{Y}^{-}$represent impurity and anionic species, respectively. Then, as a result of kinetic calculation $R_{\mathrm{p}}$ was shown to be expressed as

$$
R_{\mathrm{p}}=k_{\mathrm{p}}[\mathrm{M}]\left\{(10 I G / N) /\left(p k_{\mathrm{r},(1)}\left[\mathrm{Y}^{-}\right]+k_{\mathrm{X}}[\mathrm{X}]\right)\right\} \text {. }
$$

Here, $G$ and $N$ represent the initiating-ion yield or free-ion yield per 100-eV energy absorbed and the Avogadro number, respectively and $p k_{\mathrm{r},(1)}$ means the contribution of the diffusion of anionic charge carrier $\left(\mathrm{Y}^{-}\right)$to the recombination rate constant between $\mathrm{M}_{1}^{+}$and $\mathrm{Y}^{-}$. In the calculation in the preceding paper $^{6}$, reaction 2 was also assumed to depend on the degree of polymerization of the cation, $n$, however it is considered better to use a constant value, $k_{\mathrm{X}}$ and final consequence is given by eq 3 . In this treatment, each sample of a different batch is characterized only with impurity concentration, $[\mathrm{X}]$, and it is easily understood from eq 3 that $R_{\mathrm{p}}-I$ relationships in the samples of different [X] are nearly parallel one another as was schematically illustrated in Figure 1 in ref 10.

Therefore, Figures 2 and 3 indicate that eq 3 is not applicable to both oxygen-free and oxygencontaining examples, without modification of the equation or change of the parameters other than $[\mathrm{X}]$. Here, consider a possible influence of oxygen to elementary processes of free-cationic polymerization. If the initiating-ion yield, $G$ or the propagation rate constant, $k_{\mathrm{p}}$ were to decrease by the existence of oxygen, such polymerization behaviors as observed in Figures 2 and 3 would be expected. However, the free-ion yield is known to be governed by the bulk properties of monomer, i.e., electron density, dielectric constant, etc., which are not much influenced by a slight amount of dissolved oxygen. Further, interaction between propagating ion with oxygen which may influence the $k_{\mathrm{p}}$ value seems unlikely in this system. In the field of catalyst-initiated polymerization with cationic mechanism, at least, such a mechanism is still unknown. Concerning the termination process, two possibilities are predominant; one is the scavenging process of oxygen for the cation, and the other is the recombination reaction of cation with $\mathrm{O}_{2}{ }^{-}$which is formed by electron capture by oxygen.

In anionic polyrerization, oxygen is well known as an effective inhibitor. ${ }^{18}$ In the pulse radiolysis study of styrene, ${ }^{19}$ it has been reported that the transient absorption assigned to be styryl anion was not observed in the presence of oxygen. Therefore, in the absence of oxygen, it may be natural to consider that anionic polymerization 
is also taking place as well as cationic polymerization though the latter predominates in the reaction rate considering the effects of additives ${ }^{4}$ and copolymerization studies., ${ }^{3,20}$ In other words, in a superdry and completely oxygen-free system, all the anionic and cationic species are considered to be polymeric ions. In general, there coexists the propagating cation $\left(\mathrm{M}_{n}^{+}\right)$, impurity cation $\left(\mathrm{X}^{+}\right)$, propagating anion and probably oxygen anion, $\mathrm{O}_{2}^{-}$in the polymerizing system.

Electrical conductivity behaviors are well explained with the above consideration when it is assumed that the non-Ohmic current is due to polymeric ions. The deviation from an Ohmic relation seems to be probable because a greater resistivity to the translational motion of polymeric ion under the influence of electric field can be expected in a good solvent in which the polymer forms a solvent-swollen loose coil. As the mobility of the polymeric ion must be considerably lower than those of the impurity cation or $\mathrm{O}_{2}{ }^{-}$, a non-Ohmic relation should be expected only when both polymeric ions are predominant charge carriers in the steady state under irradiation, which corresponds to the cases in samples $\mathrm{A}$ and $\mathrm{B}$. On the contrary, an Ohmic relationship was maintained in samples $\mathrm{C}, \mathrm{E}$, and F. Deviations of the dose-rate exponent from 0.5 also give a proof for the coexistence of impurity ions and polymeric ions.

Accordingly, it was proposed that in the presence of oxygen, anionic polymerization was retarded yielding $\mathrm{O}_{2}^{-}$ion, which would recombine with polymeric cation at considerably higher rate than polymeric anion would. Here, theoretical calculations of $R_{\mathrm{p}}-I$ relationships were made for the the cases in which ionic polymerization proceeds in the presence and absence of oxygen. The details of the calculation procedures are described in the APPENDIX. Typical sets of $R_{\mathrm{p}}-I$ curves corresponding to each of the two different cases are given in Figure 5. The $p k_{\mathrm{r},(1)}$ value was determined such that one of the calculated $R_{\mathrm{p}}-I$ curves, each corresponding to different $[\mathrm{X}]$ gave the best fit to the actual $R_{\mathrm{p}}-I$ curves in sample $\mathrm{A}$ or $\mathrm{C}$, which was chosen as a representative for oxygen-free or oxygen-containing system, respectively. The curves showing the best fit to the results of

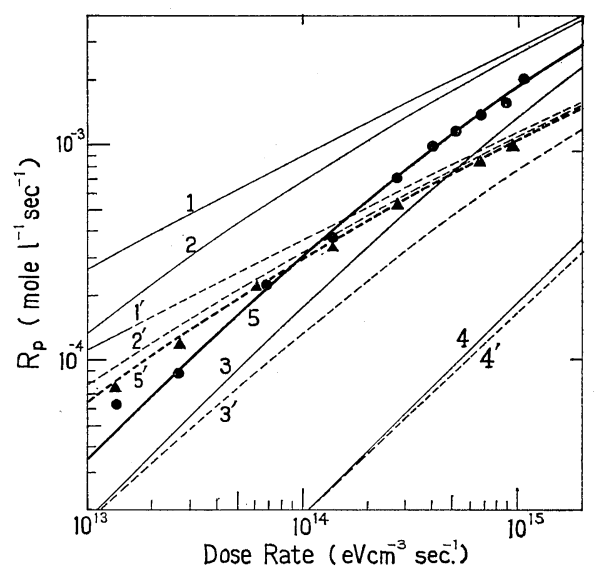

Figure 5. Calculated $R_{\mathrm{p}}$ values of as a function of dose rate: $\boldsymbol{O}$, sample A in Figure 2; $\boldsymbol{\Delta}$, sample $\mathrm{C}$ in Figure 3; a, series 1, 2, 3, 4, $p k_{\mathrm{r},(1)}=5 \times 10^{10} l \mathrm{~mol}^{-1}$ $\mathrm{sec}^{-1} ; \mathrm{b}$, series $1^{\prime}, 2^{\prime}, 3^{\prime}, 4^{\prime}, p k_{\mathrm{r},(1)}=3 \times 10^{11} l \mathrm{~mol}^{-1}$ $\mathrm{sec}^{-1}$; impurity levels $\left(k_{\mathrm{X}}[X] \mathrm{sec}^{-1}\right), 0.1\left(1,1^{\prime}\right)$, $1\left(2,2^{\prime}\right), 10\left(3,3^{\prime}\right)$, and $10^{2}\left(4,4^{\prime}\right)$.

samples $\mathrm{A}$ and $\mathrm{C}$ were obtained for $k_{\mathrm{X}}[\mathrm{X}]$ values of 1.5 and 5 assuming that $p k_{r,(1)}$ was $5 \times 10^{10}$ and $3 \times 10^{11}$, respectively. From Figure 5 , it is apparent that with greater $p k_{r,(1)}$, the maximum $R_{\mathrm{p}}$ level (curve 1 and $1^{\prime}$ ) becomes lower and the dose-rate dependence becomes smaller when compared at a fixed [X]. As the diffusion constant of oxygen ${ }^{21}$ was evaluated to be almost the same as that of water in benzene ${ }^{22}$, it is quite reasonable to assume $p k_{\mathrm{r},(1)}=k^{\prime}$ (see APPENDIX) in an oxygen-containing system. On the other hand, the smaller $p k_{\mathrm{r},(1)}$ value which fits for oxygen-free system suggests that an anionic species of relatively higher molecular weight is present in the system. However taking into account the square-root relationship between the diffusion constant of polymer and its degree of polymerization $(D P),{ }^{23}$ it is likely that the propagating cation recombines preferentially with the propagating anion having lower $D P$, probably less than 30 . Charge recombination between polymer cation and anion of higher $D P$ seems to be more difficult than expected from their diffusion constants because ionic sites are relatively small compared with the whole volume of polymer coils dissolved in monomer, as had been proposed in mutual termination process in radical polymerization. ${ }^{24}$

The absolute value of $R_{\mathrm{p}}$ at a fixed dose rate 


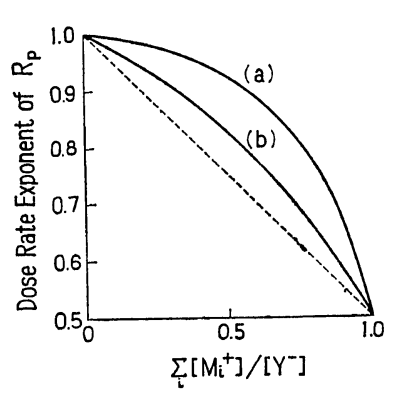

Figure 6. Calculated relationship between the relative amount of propagating ion at steady state and the dose-rate exponent of $R_{\mathrm{p}}$ : curve (a), $p k_{\mathrm{r},(1)}=5 \times 10^{10} / \mathrm{mol}^{-1} \mathrm{sec}^{-1}$; curve (b), $p k_{\mathrm{r},(1)}=3 \times$ $10^{11} l \mathrm{~mol}^{-1} \mathrm{sec}^{-1}$.

and the dose-rate exponent of $R_{\mathrm{p}}$ have been used as phenomenal measures to check the purity of monomer. However, the former by itself is an insufficient measure unless $R_{\mathrm{p}}-I$ relationship is well known at the polymerization conditions studied. A relationship between the dose-rate exponent of $R_{\mathrm{p}}$ and the fraction of propagating cation to total ion, $\Sigma\left[\mathrm{M}_{i}^{+}\right] /\left[\mathrm{Y}^{-}\right]$, at steady state has been calculated for two cases shown in Figure 5 and is shown in Figure 6. It is always true that when the relative concentration of propagating ion is 1 , the dose-rate exponent equals 0.5 and it becomes 1 when all the cation is captured by impurity. However from Figure 6 it is also apparent that the doserate exponent depends upon the $p k_{r,(1)}$ value as well as the relative concentration of propagating cation. For instance, when $\Sigma\left[\mathrm{M}_{i}^{+}\right] /\left[\mathrm{Y}^{-}\right]$is 0.87 , the dose-rate exponent equals 0.60 in an oxygencontaining system (curve b) while in an oxygenfree system (curve a) it is still 0.70. And this may be one of the reasons why the achivement of the half-power dose-rate dependence of $R_{\mathrm{p}}$ is difficult in styrene especially in an oxygen-free system. The longer lifetime of a propagating ion due to the decrease in the termination rate may be another possible reason.

Some differences have been found in polymerization behavior of styrene between the results described here and Metz's. ${ }^{8}$ He observed a quite complicated temperature dependence of $\boldsymbol{R}_{\mathrm{p}}$ in almost superdry samples. It is easily understood that the variation in polymerization temperature may induce a change in $\Sigma\left[\mathrm{M}_{i}^{+}\right] /$
[ $\mathrm{Y}^{-}$] ratio through $p k_{\mathrm{r},(i)}$ and $k_{\mathrm{X}}$ values and consequently the dose-rate dependence of $R_{\mathrm{p}}$ changes. Therefore unless the the dose-rate dependence is invariant with temperature, it seems diffiult to draw a meaningful conclusion from the apparent activation energy of $R_{\mathrm{p}}$. Negative temperature coefficients of $R_{\mathrm{p}}$ in semisuperdry sample was never observed in this experiment. Concerning the effect of oxygen addition, detailed studies of $R_{\mathrm{p}}$ as a function of oxygen concentration seems to be required as a future study.

\section{Estimation of $k_{\mathrm{p}}$ and $E_{\mathrm{p}}$}

In the samples which polymerized with relatively high rates, Ohmic law was maintained only in sample C, which showed the lowest doserate exponent of $R_{\mathrm{p}}$. Accordingly in sample C the lowest impurity concentration was indicated from the comparison with calculated $R_{\mathrm{p}}-I$ curves and it is indicated the predominance of oxygen anion as a negative charge carrier after inhibiting anionic polymerization. Although the half-power dependence of $R_{\mathrm{p}}$ on dose rate was not yet achieved in this sample, a crude evaluation of $k_{\mathrm{p}}$ was attempted using eq 3 . The freeion lifetime was approximated with $\tau$, which is defined as $^{16}$

$$
\tau=\varepsilon / 3.6 \times 10^{12} \pi \sigma
$$

where $\varepsilon$ is the dielectric constant of the medium. In Figure $7, R_{\mathrm{p}} / \tau$ was plotted against the dose rate at $25^{\circ}$ and $40^{\circ} \mathrm{C}$ for sample C. The initiatingion yield was assumed to be 0.055 at $25^{\circ} \mathrm{C}$ and 0.063 at $0^{\circ} \mathrm{C}$, which had been evaluated for benzene. ${ }^{25}$ The resulting $k_{\mathrm{p}}$ values are $1.9 \times 10^{6}$ and $2.3 \times 10^{6} l \mathrm{~mol}^{-1} \mathrm{sec}^{-1}$ at $25^{\circ}$ and $40^{\circ} \mathrm{C}$, respectively. These values can be regarded as lowest

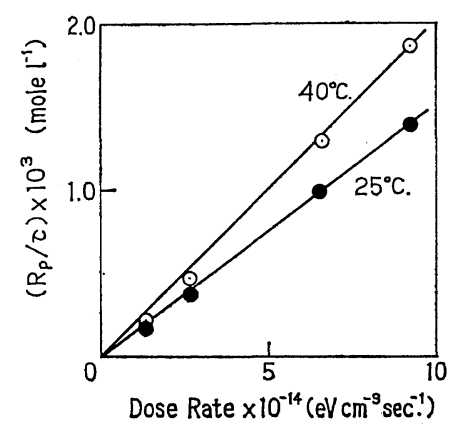

Figure 7. $\left(R_{\mathrm{p}} / \tau\right) v s$. dose rate at $25^{\circ}$ and $40^{\circ} \mathrm{C}$. 
limits of $k_{\mathrm{p}}$, because of the half-power dose-rate exponent of $R_{\mathrm{p}}$ was not realized. From the calculations shown in Figure $5, R_{\mathrm{p}}$ in superdry state can be well estimated to be $25 \pm 5 \%$ greater than that when $R_{\mathrm{p}}$ is proportional to $I^{0.60}$. This ratio is relatively insensitive to the change of parameters. Therefore the final $k_{\mathrm{p}}$ values are

$$
\begin{array}{ll}
25^{\circ} \mathrm{C} & (2.4 \pm 0.9) \times 10^{6} l \mathrm{~mol}^{-1} \mathrm{sec}^{-1} \\
40^{\circ} \mathrm{C} & (2.9 \pm 1.0) \times 10^{6} l \mathrm{~mol}^{-1} \mathrm{sec}^{-1}
\end{array}
$$

where the error limit was evaluated to be within $\pm 35 \%$.

Estimation of $E_{\mathrm{p}}$ was carried out by two different ways. From the $k_{\mathrm{p}}$ values given above $2.2 \mathrm{kcal} \mathrm{mol}^{-1}$ was obtained. Secondly, as shown previously, ${ }^{6} k_{\mathrm{p}}$ is expressed as

$$
k_{\mathrm{p}}=(N / 10 I G[\mathrm{M}])\left(R_{\mathrm{p}} / \tau\right)
$$

Then, a following relation is obtained.

$$
\begin{aligned}
\mathrm{d} \ln k_{\mathrm{p}} / \mathrm{d}\left(T^{-1}\right)= & \mathrm{d} \ln R_{\mathrm{p}} / \mathrm{d}\left(T^{-1}\right)-\mathrm{d} \ln \tau / \mathrm{d}\left(T^{-1}\right) \\
& -\mathrm{d} \ln [\mathrm{M}] / \mathrm{d}\left(T^{-1}\right)-\mathrm{d} \ln G / \mathrm{d}\left(T^{-1}\right) \\
& -\mathrm{d} \ln I / \mathrm{d}\left(T^{-1}\right) \\
= & \operatorname{dln} R_{\mathrm{p}} / \mathrm{d}\left(T^{-1}\right)+\operatorname{d} \ln \sigma / \mathrm{d}\left(T^{-1}\right) \\
& -\mathrm{d} \ln G / \mathrm{d}\left(T^{-1}\right)-2 \mathrm{~d} \ln \rho / \mathrm{d}\left(T^{-1}\right) \\
& -\mathrm{d} \ln \varepsilon / \mathrm{d}\left(T^{-1}\right) \\
= & E_{\mathrm{app}}+E_{\sigma}-E_{G}-2 E_{\rho}-E_{\varepsilon}
\end{aligned}
$$

$E_{\sigma}$ is evaluated to be $(1.6 \pm 0.3) \mathrm{kcal} \mathrm{mol}^{-1}$ in samples $\mathrm{C}$ and $\mathrm{F}$. $\quad E_{\mathrm{G}}$ is assumed to be $(1.5 \pm 0.3)$ $\mathrm{kcal} \mathrm{mol}^{-1}$ from the result for benzene. ${ }^{25}$ As temperature coefficient of density $(\rho)$ and dielectric constant are -0.17 and $-0.19 \mathrm{kcal} \mathrm{mol}^{-1}$, respectively, the result obtained is,

$$
E_{\mathrm{p}}=(2.2 \pm 1.3) \mathrm{kcal} \mathrm{mol}^{-1}
$$

The agreement of $E_{\mathrm{p}}$ values estimated by the two ways is accidentally good. The $k_{\mathrm{p}}$ and $E_{\mathrm{p}}$ values thus obtained allowed the evaluation of the frequency factor for propagation, $A_{p}$ to be $10^{8.0 \pm 1.1}$

Here it must be confirmed that this $E_{\mathrm{p}}$ value can be applied to the whole temperature range studied, $0^{\circ}-40^{\circ} \mathrm{C}$. In the first calculation, $E_{\mathrm{p}}$ was estimated from only two $k_{\mathrm{p}}$ values and in the latter method also a constant temperature coefficient was assumed. However, as discussed previously, in our results on $R_{\mathrm{p}}$ and $\sigma$, there was no evidence to suggest a complicated tem- perature dependences of $R_{\mathrm{p}}$. These $E_{\mathrm{p}}$ evaluations are crude and rather tentative, nonetheless, the obtained value is believed to be quite significant for the further discussion to elucidate the distinct feature in free-cationic propagation.

The number-average degree of polymerization, $\overline{D P}_{n}$ of the polymers obtained by free-cationic mechanism is about $400-600$, which is considerably higher than those obtained by paired-cationic polymerization. ${ }^{26-28}$ Assuming $\overline{D P}_{n}$ as $k_{\mathrm{p}} / k_{\mathrm{tr}}$, $k_{\mathrm{tr}}$ at $25^{\circ} \mathrm{C}$ was evaluated as $4.6 \times 10^{3} \mathrm{lmol}^{-1}$ $\mathrm{sec}^{-1}$. As the temperature coefficient for $\overline{D P}_{n}$ is supposed to be very small, we can well regard $E_{\mathrm{p}}-E_{\mathrm{tr}}$ as $-0.1 \pm 0.3 \mathrm{kcal} \mathrm{mol}^{-1}$.

\section{Comparison of Progagation Processes with Other} Polymerization Mechanisms.

Typical values of $E_{\mathrm{p}}$ and $\log A_{\mathrm{p}}$ in the propagation reaction of styrene by several different polymerization mechanisms are cited in Table II. At first sight, it is apparent that the obtained $k_{\mathrm{p}}$ in free-cationic polymerization is the highest among all $k_{\mathrm{p}}$ values reported and that the freecationic polymerization of bulk styrene is characterized by low $E_{\mathrm{p}}$ values compared with those in other mechanisms and relatively high $A_{\mathrm{p}}$ value. It seems natural that $A_{\mathrm{p}}$ in free-cationic, freeanionic and free-radical polymerizations are relatively large, probably exceeding $10^{7}$. To show the correlations between them clearly, an illustration as shown in Figure 8 was attempted.

Radical polymerization had been carried out also in bulk state ${ }^{29,30}$ and a great difference between $k_{\mathrm{p}}$ (radical) and $k_{\mathrm{p}}$ (free cation) is found to be due to relatively high $E_{\mathrm{p}}$ in radical polymerization. As $E_{\mathrm{p}}$ in radical polymerization of vinyl monomers are generally in the proximity of $7 \pm 1 \mathrm{kcal} \mathrm{mol}^{-1},{ }^{39}$ the observed difference in $E_{\mathrm{p}}$ can be regarded as a general trend.

It is well known that propagation process in paired ionic polymerization is greatly influenced by the nature of catalyst as well as the polarity of solvent. In the polymerization initiated by weak initiators as iodine, Higashimura ${ }^{15}$ gave an indication that the rate-determinating process for the propagation is dissociation of contact ionpair to form a $\mathrm{P}^{+} \ldots \ldots \mathrm{X}^{-}$complex in a transi-

$$
\because \mathrm{M}:
$$

tion state. The use of stannic chloride ${ }^{36}$ or boron trifluoride etherate ${ }^{37}$ increased $k_{\mathrm{p}}$ more 
Table II. Characteristic values for the propagation reactions of styrene

\begin{tabular}{|c|c|c|c|c|c|c|}
\hline & Solvent & Catalyst & $\begin{array}{c}k_{\mathrm{p}}\left(25^{\circ} \mathrm{C}\right) \\
l \mathrm{~mol}^{-1} \mathrm{sec}^{-1}\end{array}$ & $\begin{array}{c}E_{\mathrm{p}} \\
\mathrm{kcal} \mathrm{mol}^{-1}\end{array}$ & $\log A_{\mathrm{p}}$ & $\operatorname{Ref}$ \\
\hline \multirow[t]{2}{*}{ Radical } & Bulk & Light & 39.5 & 6.3 & 6.2 & 29 \\
\hline & Bulk & BPO & $35\left(20^{\circ} \mathrm{C}\right)$ & 7.8 & 7 & 30 \\
\hline \multirow[t]{5}{*}{ Paired anion } & $\mathrm{THF}$ & $\mathrm{Cs}^{+}$ & 21 & 5.35 & 5.7 & 31 \\
\hline & THP & $\mathrm{Na}^{+}$ & 14 & 6.7 & 6.0 & 32 \\
\hline & THP & $\mathrm{K}^{+}$ & 73 & 5.3 & 5.8 & 32 \\
\hline & THP & $\mathrm{Rb}^{+}$ & 83 & 4.9 & 5.5 & 32 \\
\hline & THP & $\mathrm{Cs}^{+}$ & 53 & 4.9 & 5.3 & 32 \\
\hline \multirow[t]{3}{*}{ Free anion } & THF & $\mathrm{Na}^{+}, \mathrm{Cs}^{+}$ & $6.5 \times 10^{4}$ & 5.9 & 9.05 & 31 \\
\hline & THP & $\mathrm{Li}^{+}, \mathrm{Na}^{+}$ & $6 \times 10^{4}$ & 4.8 & 8.3 & 33 \\
\hline & $\begin{array}{l}\text { Dimethoxy- } \\
\text { ethane }\end{array}$ & $\mathrm{Cs}^{+}$ & $4 \times 10^{4}$ & 5 & 8.3 & 34 \\
\hline \multirow[t]{7}{*}{ Pair cation } & $\left(\mathrm{CH}_{2} \mathrm{Cl}\right)_{2}$ & $\mathbf{I}_{2}$ & $1.8 \times 10^{-3}\left(20^{\circ} \mathrm{C}\right)$ & $6-6.5$ & $1.3-2.1$ & 35 \\
\hline & $\left(\mathrm{CH}_{2} \mathrm{Cl}\right)_{2}$ & $\mathrm{SnCl}_{4}$ & $0.42\left(30^{\circ} \mathrm{C}\right)$ & - & - & 36 \\
\hline & Benzene & $\mathrm{BF}_{3} \mathrm{OEt}_{2}$ & $0.25\left(30^{\circ} \mathrm{C}\right)$ & - & - & 37 \\
\hline & $\left(\mathrm{CH}_{2} \mathrm{Cl}\right)_{2}$ & $\mathrm{H}_{2} \mathrm{SO}_{4}$ & 7.5 & - & - & 38 \\
\hline & $\left(\mathrm{CH}_{2} \mathrm{Cl}\right)_{2}$ & $\mathrm{HClO}_{4}$ & $7-17\left(20^{\circ} \mathrm{C}\right)$ & $8.3-9.1$ & $7.4-8.0$ & 28 \\
\hline & $\begin{array}{c}\left(\mathrm{CH}_{2} \mathrm{Cl}\right)_{2} / \mathrm{CCl}_{4} \\
(75 / 20)\end{array}$ & $\mathrm{HClO}_{4}$ & $3.2\left(20^{\circ} \mathrm{C}\right)$ & 11.4 & 9.0 & 28 \\
\hline & $\underset{(55 / 40)}{\left(\mathrm{CH}_{2} \mathrm{Cl}\right)_{2} / \mathrm{CCl}_{4}}$ & $\mathrm{HClO}_{4}$ & $0.4\left(20^{\circ} \mathrm{C}\right)$ & 13.0 & 9.3 & 28 \\
\hline Free cation & Bulk & Radiation & $2.4 \times 10^{6}$ & $2.2 \pm 1.3$ & $8.0 \pm 1.1$ & This work \\
\hline
\end{tabular}

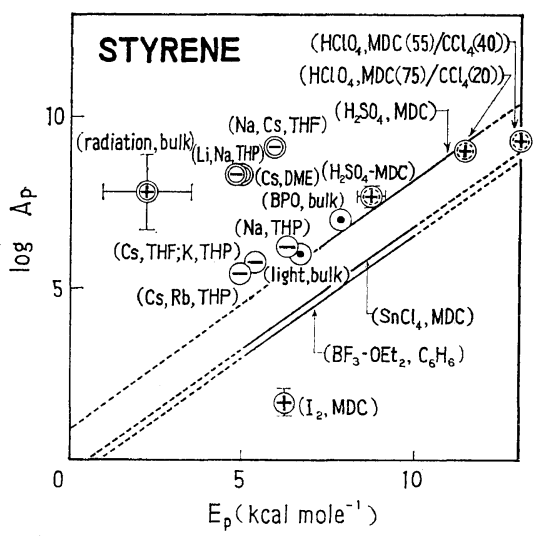

Figure 8. Relationship between $\log A_{\mathrm{r}}$ and $E_{\mathrm{p}}$ in the polymerizations of styrene.

than 100 times. Another extreme case was informed by Pepper. ${ }^{28,38}$ Using a strong protonic acid as sulphuric acid ${ }^{38}$ or perchloric acid ${ }^{28}$ in 1, 2-dichloroethane, $k_{\mathrm{p}}$ was evaluated to be approximately $10 \mathrm{lmol}^{-1} \mathrm{sec}^{-1}$, which is $10^{3}$ times times greater than that the in iodine case ${ }^{35}$ and in this case the propagating end is presumably considered to be rather free-cationic judging from its large $A_{\mathrm{p}}$ value. If so, a comparison of $E_{\mathrm{p}}\left(\mathrm{HClO}_{4}\right)$ with $\mathrm{E}_{\mathrm{p}}$ (free cation) should be dis- cussed in terms of a solvent effect on the freecationic polymerization and observed tendency in $E_{\mathrm{p}}$ seems reasonable when solvation of propagating cation in polar solvent is taken into account. However this consequence is inconsistent with Pepper's result ${ }^{28}$ which was carried out in mixed solvent system. Anyhow the effects of solvent polarity on the propagation processes in ionic polymerization, free or paired, are one of the most important problem remained for future study.

On the other hand, in the case of anionic polymerization there has been informed several instances in which free- and paired-ionic polymerizations proceeded simultaneously in the same system. $^{31}$ There, it was found that with the change from paired-ionic to free-ionic mechanism, $A_{\mathrm{p}}$ increased by a factor of $10^{2}-10^{3}$ while $E_{\mathrm{p}}$ was almost invariable, and similar experiments are strongly expected also in the case of cationic polymerization. Although several experimental difficulties still prevent a comparison of $k_{\mathrm{p}}$ (freecationic) and $k_{\mathrm{p}}$ (free-anionic) in the same system, the author is confident of the predominance of cationic mechanism over anionic one in radiation-induced polymerization of styrene on the 
basis of the additive effects ${ }^{3,4}$ and copolymerization studies. ${ }^{3,20}$

The above-mentioned discussions about styrene are partly inconsistent with the previous findings on IBVE, ${ }^{6}$ in which particularly, a higher $E_{\mathrm{p}}$ compared with paired-cationic mechanism was observed. However it has been pointed out that vinyl ethers sometimes show strange polymerion behaviors in their reactivity from other vinyl monomers ${ }^{15}$ and, in the succeeding paper, ${ }^{20}$ has been attempted the elucidation of the difference in the kinetic behavior between styrene and IBVE.

\section{APPENDIX}

Here consider an extreme case where there exists only one kind of anionic species, $\mathrm{Y}^{-}$, regardless of its species, $\mathrm{O}_{2}{ }^{-}$or polymeric anion. Involvement of the coexistence of two anionic species in the kinetics was excluded because it requires too many unknown parameters, i.e., rate constants, concentrations, etc., to comprehend the outline of polymerization. From eq 9 and 12 in ref 6 along with eq 3 in this paper, a follwing cubic equation as to $\left[\mathrm{Y}^{-}\right]$is obtained,

$$
\begin{gathered}
p k_{\mathrm{r},(1)} k_{\mathrm{r},(\mathrm{X}),}\left[\mathrm{Y}^{-}\right]^{3}+k_{\mathrm{X}} k_{\mathrm{r},(\mathrm{x})}[\mathrm{X}]\left[\mathrm{Y}^{-}\right]^{2} \\
-k_{\mathrm{r},(\mathrm{X})} R_{i}\left[\mathrm{Y}^{-}\right]-k_{\mathrm{X}}[\mathrm{X}] R_{i}=0,
\end{gathered}
$$

here,

$$
R_{i}=10 I G / N .
$$

It is clear that ${ }^{6}$

$$
\begin{gathered}
\sum\left[\mathrm{M}_{n}^{+}\right]+\left[\mathrm{X}^{+}\right]=\left[\mathrm{Y}^{-}\right] \\
k_{\mathrm{X}}[\mathrm{X}] \Sigma\left[\mathrm{M}_{n}^{+}\right]=k_{\mathrm{r},(\mathrm{X})}\left[\mathrm{X}^{+}\right]\left[\mathrm{Y}^{-}\right]
\end{gathered}
$$

When all the parameters except $\left[\mathrm{Y}^{-}\right]$in eq A-1 are known, eq $\mathrm{A}-1$ gives only one positive solution and then, using eq A-3 and A-4, all the ion concentrations $\left[\mathrm{Y}^{-}\right], \Sigma\left[\mathrm{M}_{n}^{+}\right]$and $\left[\mathrm{X}^{+}\right]$can be evaluated at a fixed dose rate. Then $R_{\mathrm{p}}-I$ curves for a fixed impurity concentration, $[\mathrm{X}]$ are computed varying $I$ in eq A-2. Therefore when all the rate constants in eq A-1-A-3 are known including $k_{\mathrm{p}}$, a set of $R_{\mathrm{p}}-I$ curves are obtained changing $[\mathrm{X}]$, which is illustrated in Figure 5.

From the definition of $p k_{r,(1)}$ stated previously, it is obvious that

$$
p k_{r,(1)}=k_{r,(\mathrm{x})}-k^{\prime}
$$

$k_{\mathrm{r}, \mathrm{x} \text { ) }}$ represents the rate constant for the recombination reaction between $\mathrm{X}^{+}$and $\mathrm{Y}^{-}$and therefore $k^{\prime}$ corresponds to $k_{\mathrm{r},(\mathrm{X})} \times D_{\mathrm{X}+/\left(D_{\mathrm{X}}++\right.}$ $\left.D_{\mathrm{Y}^{-}}\right)$, i.e., the contribution of $\mathrm{X}^{+}$diffusion to $k_{r,(x)}$. As water is a major impurity in inhibiting the cationic polymerization, $k^{\prime}$ is presumably evaluated to be $3 \times 10^{11} \mathrm{lmol}^{-1} \mathrm{sec}^{-1}$, calculated on the basis of the diffusion constant of water in benzene ${ }^{22}$ using the equation, ${ }^{40} \mu / D=e / k T$ and Langevin's equation, ${ }^{41} k / \mu=4 \pi e / \varepsilon$, where $\mu$ denotes mobility. $G$ was assumed to be 0.055 $\left(25^{\circ} \mathrm{C}\right)$ which was determined for benzene ${ }^{25}$ and $k_{\mathrm{p}}=2.4 \times 10^{6} l \mathrm{~mol}^{-1} \mathrm{sec}^{-1}$ was used. Then a set of $R_{\mathrm{p}}-I$ curves can be calculated for a suitable choice of $p k_{\mathrm{r},(1)}$.

Acknowledgements. The authors are grateful to Prof. T. Higashimura and Dr. Y. Imanishi of Kyoto University for valuable discussions.

\section{REFERENCES}

1. T. H. Bates, J. V. F. Best, and T. F. Williams, J. Chem. Soc., 1531 (1962).

2. J. V.F. Best, T. H. Bates, and T.F. Williams, Trans. Faraday Soc., 58, 192 (1962).

3. K. Ueno, Ko. Hayashi, and S. Okamura, Polymer, 7, 431 (1966).

4. K. Ueno, F. Williams, Ko. Hayashi, and S. Okamura, Trans. Faraday Soc., 63, 1478 (1967).

5. D. J. Metz, "Irradiation of Polymer," Advances Chemistry Series, No. 66, American Chemical Society, Washington D. C., 1967, p 171.

6. Ka. Hayashi, Ko. Hayashi, and S. Okamura, $J$. Polym. Sci., Part A-1, 9, 2305 (1971).

7. R. B. Taylor and F. Williams, J. Amer. Chem. Sci., 91, 3728 (1969).

8. R. C. Potter and D. J. Metz, J. Polym. Sci. Part A-1, 9, 441 (1971).

9. E. Hubman, R. B. Taylor, and F. Williams, Trans. Faraday Soc., 62, 88 (1966).

10. F. Williams, Ka. Hayashi, K. Ueno, Ko. Hayashi, and S. Okamura, ibid., 63, 1501 (1967).

11. G. R. Freeman, J. Chem. Phys., 39, 988 (1963).

12. A. Hummel, A. O. Allen, and F. W. Watson, Jr., ibid., 44, 3431 (1966).

13. F. Williams, J. Amer. Chem. Soc. 86, 3954 (1964).

14. A. Mozumder and J. L. Magee, J. Chem. Phys., 47, 939 (1967). A. Mozumder, ibid., 48, 1659 (1968). 
15. T. Higashimura, "Structure and Mechanism in Vinyl Polymerization," T. Tsuruta and K.F. O'driscoll, Ed., Dekker, New York, N.Y., 1969, pp 334-336.

16. Ka. Hayashi, Y. Yamazawa, T. Takagaki, F. Williams, Ko. Hayashi, and S. Okamura, Trans. Faraday Soc., 63, 1489 (1967).

17. J. F. Westlake and R. Y. Huang, J. Polym. Sci., Part $A-1$, 10, 1443 (1972).

18. M. Szwarc, "Carbanions, Living Polymers and Electron Transfer Processes,' Interscience, New York, N.Y., 1968, p 22.

19. D. J. Metz, R. C. Potter, and J. K. Thomas, J. Polym. Sci. Part A-1, 5, 877 (1967).

20. Ka. Hayashi, Ko. Hayashi, and S. Okamura, Polymer J., in press.

21. I. M. Krieger, G. W. Mulholand, and C. S. Dickey, J. Phys. Chem., 71, 1123 (1967).

22. R. S. Sitaraman, A.I. Ch. E.J., 8, 277 (1962).

23. S. I. Klenin, V. L. Migdal, S. V. Bushin, and V. N. Tsvetkov, Vysokomol. Soedin., 8, 882 (1966).

24. S. W. Benson and A. M. North, J. Amer. Chem. Soc., 81, 1339 (1959), ibid., 84, 935 (1962).

25. W. F. Schmidt and A. O. Allen, J. Chem. Phys., 52, 2345 (1970).

26. S. Okamura, T. Higashimura, and Y. Sakurada, Kogyo Kagaku Zasshi (J. Chem. Soc. Japan, Ind. Chem. Sect.), 61, 1640 (1958).

27. A. Gandini and P. H. Plesch, J. Chem. Soc., 4846 (1965).
28. D. C. Pepper and P. J. Reilly, Proc. Roy. Soc. (London), A291, 41 (1966).

29. G. M. Burnett, Trans. Faraday Soc., 46, 772 (1950).

30. M.S. Matheson, E. E. Auer, E. B. Bevilacqua, and E. J. Hart, J. Amer. Chem. Soc., 73, 1700 (1951).

31. T. Shimomura, K. J. Tolle, J. Smid, and M. Szwarc, ibid., 89, 796 (1967).

32. F. S. Dainton, K. J. Ivin, and R. T. Laflair, Eur. Polym. J., 5, 379 (1969).

33. M. Van Beylen, M. Fisher, J. Smid, and M. Szwarc, Macromolecules, 2, 575 (1969).

34. T. Shimomura, J. Smid, and M. Szwarc, $J$. Amer. Chem. Soc., 89, 5743 (1967).

35. N. Kanoh, T. Higashimura, and S. Okamura, Makromol. Chem., 56, 65 (1967).

36. N. Kanoh, T. Higashimura, and S. Okamura, Kobunshi Kagaku (Chem. High Polymers), 19, 181 (1962).

37. T. Higashimura, H. Kusano, T. Masuda, and S. Okamura, J. Polymer Sci., Part B, 9, 463 (1971).

38. M. J. Hayes and D. C. Pepper, Proc. Roy. Soc. (London), A263, 58, 63 (1961).

39. P. J. Flory, "Principles of polymer chemistry," Cornell Univ. Press, Ithaca, N.Y., 1952, p 158.

40. H. A. Kramers, Physica, 18, 665 (1952).

41. P. Langevin, Ann. Chim. Phys., VII, 28, 433 (1903). 